\title{
THE RELATIONSHIP BETWEEN EMPLOYEE HEALTH, QUALITY CULTURE AND ORGANIZATIONAL EFFECTIVENESS: FINDINGS FROM THE LITERATURE
}

\author{
R. SADIA \\ Department of Industrial Engineering and Management, Shenkar College of Engineering and Design, Israel.
}

\section{ABSTRACT}

Organizations are complex social systems, and as such, they ought to be approached through a systems thinking viewpoint in order to understand the whole rather than just the parts. The purpose of this literature review is to outline the complex interdependent relationship between organizational effectiveness, employees' health and quality culture. This review will open with the notion of organizations as complex social systems. Then, it will describe possible applications of systems thinking in two parts: The first part will discuss quality and quality culture, and the second part will discuss employees' health in the organization. The review will include the application of system thinking and will show the important contribution of the system approach to the achievement of organizational effectiveness.

Keywords: employee health, organization health and effectiveness, stress, systems thinking.

\section{INTRODUCTION}

Numerous theories and studies deal with various aspects of improving organization's effectiveness as it undergoes change. In many studies ([1-6] and others), the emphasis has been on quality directed towards attaining customer satisfaction as the primary long-term objective above and beyond maximizing shareholder value [3]. Focusing on quality rather than focusing on organization's effectiveness represents a paradigm shift in management thinking. The quality management paradigm is based on behavioral approaches that can enhance performance by recognizing the employee as a customer and emphasizing teamwork and participation as vehicles for job satisfaction, motivation, and organizational performance [7-9]. Despite the presumed benefits from this paradigmatic stress on quality, there has been little emphasis on the importance of the employee's quality of life at work as a quality component.

The importance of considering all the components in an organization as parts of a whole system has triggered consideration of the systems approach, a paradigm that views a system as a group of interdependent, interacting parts [10]. The concept of systems thinking has been regarded as an important characteristic of total quality formulations $[4,11]$. It was also accepted later as an important core value of performance excellence by the MBNQA (Malcolm Baldrige National Quality Award) [12] and by ISO 9001: 2000 [13]. Despite this, employee health is viewed as a separate issue and not sufficiently important for strategic quality initiatives. Only lately has the interaction between employee health and organizational effectiveness started to intrigue researchers who have begun to turn their attention to ways of advancing employee health in order to improve an organization's productivity [14-17]. The interaction between quality culture and employee health is also a subject of recent interest [18-20]. Unfortunately, the literature generated by the interest in these three constructs, employee health, quality culture and organizational effectiveness, does not focus on the systems approach as a tool for understanding the relationships between these three concepts.

In the following paper, the literature review deals with quality programs, employee health and organizational effectiveness. A discussion of systems thinking and its basic concepts follows. Based on the literature and the use of the systems thinking tools, the key inter-relationships between many variables that relate to quality culture, employee health and organizational effectiveness are presented. 


\section{LITERATURE REVIEW}

2.1 Quality programs, quality culture and organizational effectiveness

In the 1990s, much of the literature concerning quality in organizations was devoted to the study of the relationships between quality and other important measures of organizational success, such as productivity [21]; profitability [22]; market value [23]; competitive advantage [24]; and organizational performance $[9,25,26]$. The reason for this focus may have been that the previously prevailing mindset in which quality by itself was not regarded as the end of a process, but as a means to something else. Only later did organizations discover that certain quality approaches, such as zero-defects or six-sigma might also be associated with effectiveness goals [27].

Many researchers investigated the reasons for the lack of success in implementing TQM in the workplace $[7,28-30]$. Some $[8,28,31]$ concluded that the low rate of TQM success was a result of focusing mostly on the 'hard' issues and neglecting the 'soft' issues when implementing TQM. 'Hard' issues were regarded [8] as core quality practices and had a more technical orientation [32]. Among these issues were quality information, process management, product design and statistical process control. The 'soft' issues were [8] infrastructure quality practices and involved more of the social and behavioral attributes of quality management [32]. Among these issues were: employer-employee relationships, top management support, customer involvement and other human relationships. At the root of the many cases of failure in the process of TQM implementations was the emphasis on quality products rather than quality interactions, and not viewing the employee as one of the main customers and the most important stakeholder of the organization [33]. Failure in implementing TQM could mostly be related to the elements that support the implementation process like the lack of support of the company leadership, rather than to the quality practices themselves [28].

Most of the literature that deals with organizational quality culture focuses on the need for a paradigm change with respect to the prevailing concepts and attitudes that are required in order for quality programs to work [34,35]. A different approach to this issue is presented by Detert et al. [36] who constructed a general framework in terms of culture that can be linked to improvement initiatives in organizations. In their study, they demonstrated a link between this framework and TQM values and beliefs and presented eight dimensions that are most frequently discussed in the literature, like ideas about stability versus change and others.

\subsection{Employee health and organizational effectiveness}

At the beginning of the 1970s, organizations moved from viewing workforce health in its relation to organizational performance to a more proactive approach, and designed programs that reinforced lifestyle changes $[37,38]$. The main concept underlying these programs was that the individual's lifestyle contributed directly to a person's health and organizations need to help individuals change their unhealthy lifestyles. While these programs continue to flourish, other researchers pointed to the link between environmental factors and employee health, especially the effect that stress (an individual's physical and mental reaction to environmental demands or pressures) has on an employee's health $[5,39,40]$.

The literature concerning the relationship between health initiatives and organizational effectiveness is far from being consistent in terms of the methods, terms and approaches that measure and evaluate organizational effectiveness and what influences it. The most frequently used term in the health promotion literature is productivity rather than effectiveness or performance. Even when authors use the word productivity, they are actually referring to one measure they believe represents productivity - absenteeism. While acknowledging this shortcoming, they explain it by the fact that methodologies for measuring productivity are lacking. 
Later, certain researchers have started to view health in a broader context, specifically when dealing with an organization's health. Grawitch et al. [41] identified five general categories of healthy workplace practices in organizations that were linked to employee well-being and organizational improvements: work-life balance, employee growth and development, health and safety, recognition, and employee involvement. According to Rosen [42], in healthy companies, products and profits are not the immediate goal; they are the result of doing everything else right. Organizational success, improved quality, better service and competitive advantage are the by-products of shared values and collective efforts.

\subsection{Systems thinking}

The systems approach distinguishes itself from the more traditional analytical approaches by emphasizing the interactions and connections between the different components of a system. The interactions of the parts become more relevant to understanding the system than understanding the parts. According to systems thinking, system behavior results from the effects of complex feedback systems.

\subsubsection{System thinking tools}

System thinking tools may be regarded as a way of describing a story. The picture shows the elements that depict the fundamental issues of a situation with arrows between them representing the influence that one element has on another. These links reveal cycles that continually repeat themselves, causing the situations to either get better or worse over time. These loops comprise a representation of causality called a feedback loop [43]. An arrow between two variables might describe a positive effect, meaning that if one variable increases (decreases) so does the affected variable, all else being equal. A negative effect is caused when one variable increases (decreases) and causes the other variable to decrease (increase), all else being equal.

There are two sets of behavioral structures: the reinforcing feedback loop and the balancing feedback loop. Figure 1 shows a reinforcing process, which generates exponential growth or collapse at an ever-increasing rate (Fig. 1):

The reinforcing feedback loop in Fig. 1 demonstrates how cause and effect reinforce each other over time, such that an increase in the cause brings about an increase in the effect, and vice versa.

Balancing processes generate forces of resistance that eventually limit growth. All balancing processes contain a self-correcting or governing function that attempts to attain some goal or target. Figure 2 shows how balancing processes are characterized by a gap between actual and desired performance.

As it can be seen in Fig. 2, when the gap between the desired and the current state is large, more actions must be taken to make a large improvement in the current state. A large

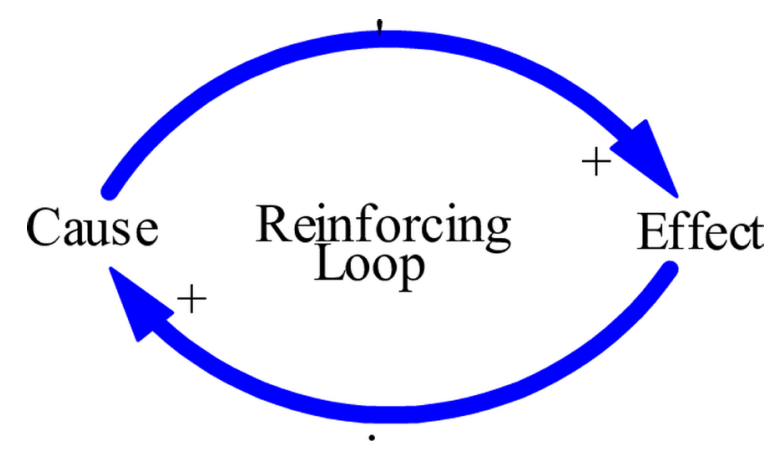

Figure 1: Reinforcing feedback loop. 


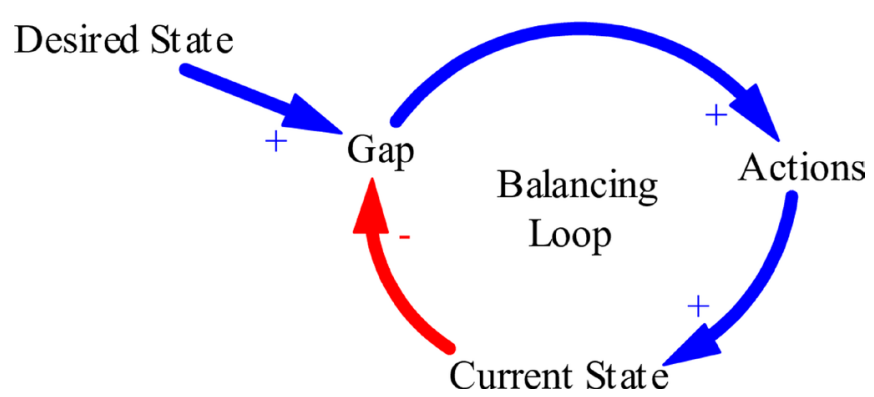

Figure 2: Balancing feedback loop.

improvement in the current state, then, lowers the gap, thus requiring fewer actions for the current state.

It is also important to notice that there may be delays, possibly of different durations, associated with the interactions between the parts of a system. These delays will determine the length of time it takes for the characteristics of the structure to become evident.

To understand the complexity of a problem, the problem has to be identified by describing verbally the relationships between all the components of the system and then the conceptual model is built, describing visually these relationships using casual feedback loops and stating the dynamics hypotheses that describe the behavior of the system over time.

\section{THE CONCEPTUAL MODEL}

The aim of this literature review was to build a holistic framework that will focus simultaneously on promoting organizational and employees' outcomes, assuming that a balance between these two outcomes is the best for both the organization and its employees in the long-run. The literature review provides the researchers with a tool to explore ways in which quality culture and employee health interact and mutually influence each other and then impact organizational effectiveness. The estimated hypothesis is worded using dynamic hypothesis. A dynamic hypothesis is a potential explanation of how the system structure causes the observed dynamic behavior as a result of the interactions between several factors in the system over time [44]. The following dynamic hypotheses were developed following the literature review summarized previously. The relevant studies that provided inspirations for each of the dynamic hypotheses will be mentioned at the end of each description.

\subsection{The dynamic hypotheses}

The first dynamic hypothesis (Learning Loop in Fig. 3) says that to operate effectively in an organization, a manager or employee should be involved in a learning process that influences his mental models (perceptions), so that he can develop new ways of thinking which can lead to a greater acceptance of change and growth. Assuming that there is a desire for this kind of learning and openness, this may result in closing the gap between the current mental models (defined by the collective skills, knowledge and experience) one has and the new mental models one encounters. The effort to close this gap will lead to decisions and then to actions that one needs to take in order to achieve more experience, skills and knowledge. This effort in turn leads to more learning and a greater degree of openness leading to new skills and the motivation to minimize the gap between the desired and achieved level of learning and openness (based on [43,45]).

The second dynamic hypothesis (Stress/Control Loop in Fig. 3) describes that the more experience gained through the development of one's skills and knowledge, the more control one has over 


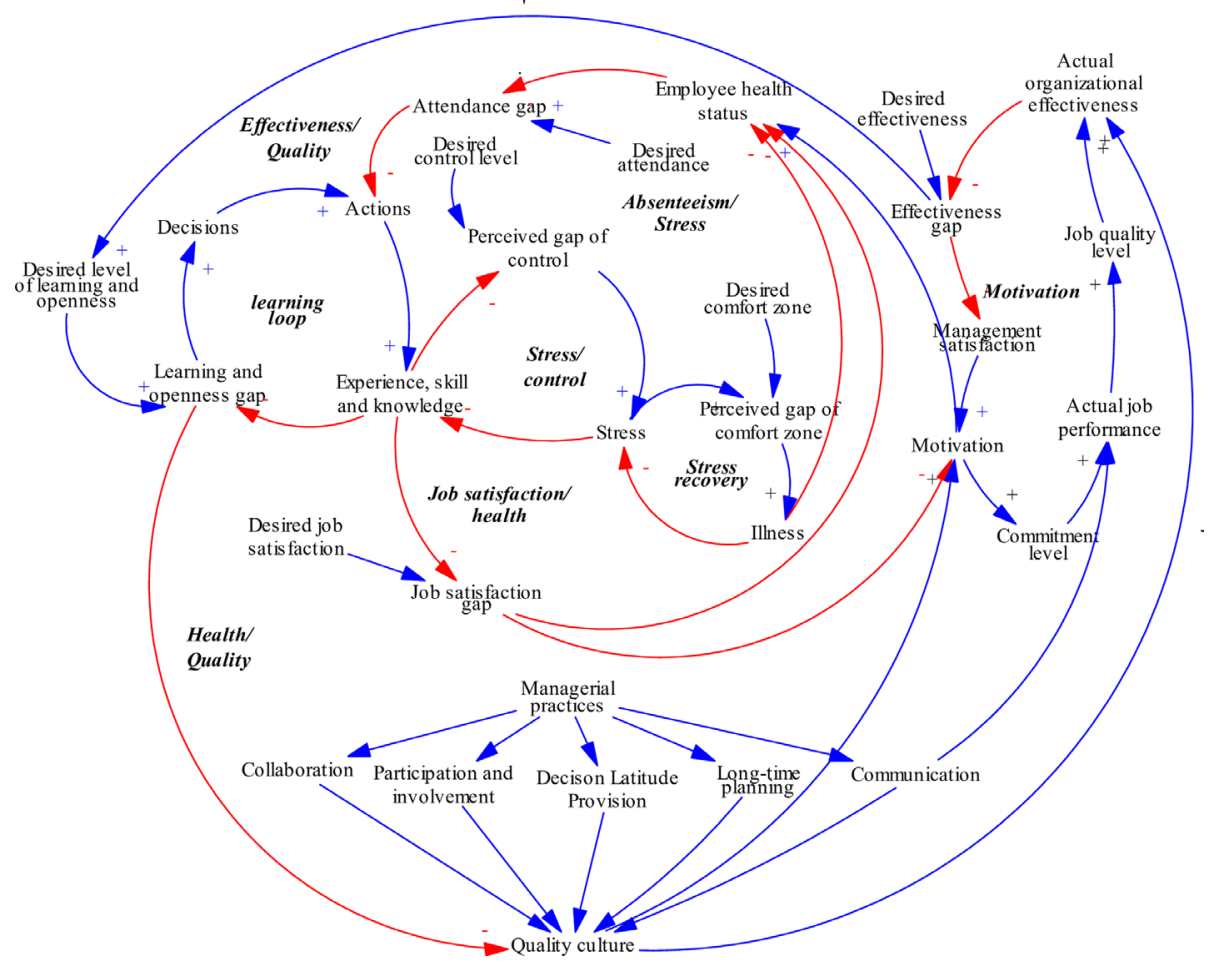

Figure 3: The full qualitative model derived from the literature.

his life. The greater the alignment between the sense of control (represented by experience, skills and knowledge) and the desire for control (which is measured in the same way), the less the perceived gap between the desired control and the perceived control. Consequently, less stress is introduced into one's life. This in turn encourages a person to look for more experience and more learning opportunities (based on [5,14,39,40]).

The third dynamic hypothesis (Job Satisfaction/Health Loop in Fig. 3) phrases that the more experience, skills and knowledge the individual gains, the greater the job satisfaction one feels as long as the perception of the level of collaboration, the level of decision latitude, and the level of participation and involvement are close to the levels that one desires. According to the literature, these concepts define important components of job satisfaction. The closer the level of job satisfaction is to the desired level of job satisfaction, the more one feels pleased (this relationship is assumed as part of the link between job satisfaction gap and employee health). Subsequently, this pleasure positively influences one's state of health. If an employee experiences an increased sense of well-being, he tends to be less absent and more productive at work. This in turn provides him with more opportunities to take more actions and develop more skills and knowledge (based on [5,16,17,39]).

The fourth dynamic hypothesis (Stress Recovery Loop in Fig. 3) says that lack of knowledge and skills leading to a feeling of lack of control increases stress up. If this build-up is accompanied by a low perceived level of decision latitude, then stress accumulates even more. This causes a person to experience a greater distance from his/her desired comfort zone. The greater the perceived gap with respect to one's comfort zone, the greater the chances that he will get sick, a state that provides him with an escape route to lower his/her stress (based on $[5,39,40]$ ). This dynamic hypothesis deals with the linkage between stress and illness. 
The fifth dynamic hypothesis (Absenteeism/Stress Loop in Fig. 3) explains that the low health status of an employee may lead to absenteeism reducing a person's productivity and the ability to acquire more skills, experience and knowledge, which increases his/her attendance gap, subsequently causing the person to be less productive and therefore, hindering one's ability to acquire more skills, experience and knowledge. This state, in turn, increases the perceived control gap, leading to even greater stress. As stress accumulates, the perceived comfort zone gap increases, eventually causing even more illness (based on [5,16,17,39]).

The sixth dynamic hypothesis (Motivation Loop in Fig. 3) says that the greater the job satisfaction one experiences, the more motivation one has at work. When motivation is high, commitment is also high, which positively influences the actual job performance. This holds true as long as the level of communication needs with the other workers is commensurate with the job requirements. If actual job performance is high, the job quality level is high, resulting in a higher level of actual organizational effectiveness. When the actual organizational effectiveness rises, the effectiveness gap decreases and management satisfaction increases. This positively influences employee satisfaction and motivation (based on [20]).

The seventh dynamic hypothesis (Health/Quality Loop and Effectiveness/ Quality Loop in Fig. 3) describes that quality culture increases with an increase in the implementation of such managerial practices as collaboration, expanded decision latitude, participation and involvement, better communication and long-term planning. Quality culture positively impacts employee motivation as well employee health status and actual organizational effectiveness. These developments decrease employee attendance gaps (the gap between the desired attendance at work and the actual attendance) and the organizational effectiveness gap. This in turn increases the actions at work taken by the employee and increases his current experience, skills and knowledge. More experience and knowledge decrease the openness gap (the gap between the current experience, skills and knowledge and the desired level of learning and openness) and finally increases quality culture (based on $[20,34,36,47])$.

\subsection{The full qualitative model}

Based on the dynamic hypotheses that were extracted from the literature, a conceptual model was constructed, demonstrating the linkage among the variables and processes that are significant components of quality culture, employee health and organizational effectiveness. Figure 2 presents the unified model, which was constructed by linking all the previously described loops.

While all the relationships and connections in Fig. 3 are important for an organization, one can conclude that the most significant loops for the purpose of this research are the Health/Quality and the Effectiveness/Quality loops and the Motivation loop, since they highlight the connection between quality culture employee health and organizational effectiveness and how they mutually influence each other.

\section{CONCLUSIONS AND RECOMMENDATIONS}

This paper contributes to the complex systems literature by exploring the relationships between several components that are usually explored individually in research. The review starts from the notion that organizations are social systems. Management practices, organizational culture and organizational values are not separate entities that can be looked in isolation and measured in relation to the organizational and employees outcome, nor can the organizational outcome be detached from employees' outcome, since they are deeply interrelated. In complex systems, especially in complex social systems like organizations, systems thinking can provide a better and more useful approach to capture the dynamic of the system. 
Viewing organizations as systems requires the use of interdisciplinary tools that are aimed at improving organizational and employee outcomes. Neither health nor effectiveness is the objective construct. The way they are perceived is always related to their cultural context. What can be considered effective in a certain organization, in a certain situation or environment, could easily be considered ineffective in a different situation. The same holds for health. When we consider any social system one have to take into account psychological and social measures, beside the objective, quantitative measures which are commonly used.

Both health and effectiveness are multi-dimensional phenomena involving interdependent physical, psychological and social aspects. Each one of these aspects can affect the individual health or the organizational effectiveness, or be affected by them. These multiple dimensions of health and effectiveness will affect one another and will bring the system to its optimal state only when they are balanced and integrated.

The use of feedback loops in building the conceptual model offers the ability to identify ongoing patterns in organizations according to the literature. On the basis of this review, case studies in various organizations with different kinds of cultures and backgrounds should be studied and investigated to determine whether the relations described in the conceptual model exist in real-life social systems. Other studies can go even further and translate the conceptual model into a formal, quantitative representation. After this quantification, it can be simulated so that one can understand its behavior over time. Overall, using a system approach for constructing a conceptual model which depicts the complexity of the organization can prove useful for understanding the linkage between organizational effectiveness, employee health and quality culture.

\section{REFERENCES}

[1] Jiang, J.Y. \& Liu, C.W., High performance work systems and organizational effectiveness: The mediating role of social capital. Human Resource Management Review, 25, pp. 126-137, 2015. doi: http://dx.doi.org/10.1016/j.hrmr.2014.09.001

[2] Matthews, J.R., Assessing organizational effectiveness: the role of performance measures. Library Quarterly, 81(1), pp. 83-110, 2011. doi: http://dx.doi.org/10.1086/657447

[3] Koys, J.D., The effects of employee satisfaction, organizational citizenship behavior, and turnover on organizational effectiveness: a unit-level, longitudinal study. Personnel Psychology, 54, pp. 101-114, 2001. doi: http://dx.doi.org/10.1111/j.1744-6570.2001.tb00087.x

[4] Deming, W.E., The New Economy, MIT Center for Advanced Engineering Study: Cambridge, MA, 1994.

[5] Karasek, R. \&Theorell, T., Healthy Work: Stress, Productivity, and the Reconstruction of Working Life. Basic Books, Inc: New York, NY, 1990.

[6] Argyris, C., Overcoming Organizational Defenses. Facilitating Organizational Learning, Allyn and Bacon: Boston, MA, 1990.

[7] Beer, M., Why total quality management programs do not persist: the role of management quality and implications for leading a TQM transformation. Decision Sciences, 34(4), pp. 623-641, 2003. doi: http://dx.doi.org/10.1111/j.1540-5414.2003.02640.x

[8] Fotopoulos, B.C. \& Psomas, L.E., The impact of "soft" and "hard" TQM elements on quality management results. International Journal of Quality \& Reliability Management, 26(2), pp. 150-163, 2009. doi: http://dx.doi.org/10.1108/02656710910928798

[9] Anderson, M. \& Sohal, A.S., A study of the relationship between quality management practices and performance in small businesses. International Journal of Quality and Reliability Management, 16(9), pp. 859-877, 1999. doi: http://dx.doi.org/10.1108/02656719910289168

[10] Sterman, D.J., Business Dynamics, Systems Thinking and Modeling for a Complex World, Irwin McGraw-Hill: New York, NY, 2000. 
[11] Deming, W.E., Out of the Crisis, MIT Center for Advanced Engineering Study: Cambridge, MA, 1986.

[12] Malcolm Baldrige National Quality Award (MBNQA), Criteria for Performance Excellence, NIST: Washington, DC, 2008.

[13] International Organization for Standardization, Quality Management Systems - Requirements, ISO 9001:2000, ISO Publication: Switzerland, 2000.

[14] Hasson, H., Brisson, C., Guérin, S., Gilbert-Ouimet, M., Bari-Gingras, G., Vézina, M. \& Bourbonnais, R., An organizational-level occupational health intervention: employee perceptions of exposure to changes, and psychosocial outcomes. Work \& Stress, 28(2), pp. 179-197, 2014. doi: http://dx.doi.org/10.1080/02678373.2014.907370

[15] Wilson, G.M., Basta, B.T., Bynum, H.B., DeJoy, M.D., Vandenberg, J.R. \& Dishman, K.R., Do intervention fidelity and dose influence outcomes? Results from the move to improve worksite physical activity program. Health Education Research, 25(2), pp. 294-305, 2010. doi: http:// dx.doi.org/10.1093/her/cyn065

[16] Riedel, E.J., Lynch, W., Baase, C., Hymel, P. \& Peterson, W.K., The effect of disease prevention and health promotion on workplace productivity: a literature review. American Journal of Health Promotion, 15(3), pp. 167-191, 2001. doi: http://dx.doi.org/10.4278/0890-117115.3.167

[17] Berger, L.M., Murray, F.J., Xu, J. \& Pauly, M., Alternative valuations of work loss and productivity. Journal of Occupational and Environmental Medicine, 43(1), pp. 18-24, 2001. doi: http://dx.doi.org/10.1097/00043764-200101000-00005

[18] Lagrosen, Y., Bäckström, I. \& Lagrosen, S., The relationship between quality management and health-exploring the underlying dimensions. International Journal of Productivity and Quality Management, 5(2), pp. 109-123, 2010. doi: http://dx.doi.org/10.1504/ijpqm.2010.030737

[19] Baptiste, N.R., Tightening the link between employee well-being at work and performance: a new dimension for HRM. Management Decision, 46(2), pp. 284-309, 2008. doi: http:// dx.doi.org/10.1108/00251740810854168

[20] Browne, H.J., Benchmarking HRM practices in healthy work organizations. American Business Review, 18(2), pp. 54-61, 2000. doi: http://dx.doi.org/10.1037/e359922004-005

[21] Benavides-Chicon, C.G. \& Ortega, B., The impact of quality management on productivity in the hospitality sector. International Journal of Hospitality Management, 42, pp. 165-173, 2014. doi: http://dx.doi.org/10.1016/j.ijhm.2014.07.004

[22] Singhal, R.V. \& Hendricks, B.K., The financial justification of TQM. Center for Quality of Management Journal, 8(1), pp. 1-19, 1999.

[23] Lin, C. \& Su, C., The Taiwan nation quality award and market value of the firms: an empirical study. Production Economics, 144, pp. 57-67, 2013. doi: http://dx.doi.org/10.1016/j.ijpe.2013.01.015

[24] Powell, C.T. Total quality management as competitive advantage: a review and empirical study. Strategic Management Journal, 16, pp. 15-37, 1995. doi: http://dx.doi.org/10.1002/smj.4250160105

[25] Macinati, S.M., The relationship between quality management systems and organizational performance in the Italian National Health Service. Health Policy, 85, pp. 228-241, 2008. doi: http://dx.doi.org/10.1016/j.healthpol.2007.07.013

[26] Samson, D. \& Terziovski, M., The relationship between total quality management practices and operational performance. Journal of Operations Management, 17, pp. 393-409, 1999. doi: http://dx.doi.org/10.1016/s0272-6963(98)00046-1

[27] Sudit, F.E., Effectiveness, Quality and Efficiency: A Management Oriented Approach, Kluwer Academic Publishers: Boston, MA, 1996.

[28] Yamada, T.T., Poltronieri, F.C., Gambi, N. do L. \& Gerolamo, C.M., Why does the implementation of quality management practices fail? A qualitative study of barriers in 
Brazilian companies. Social and Behavioral Sciences, 81, pp. 366-370, 2013. doi: http:// dx.doi.org/10.1016/j.sbspro.2013.06.444

[29] Page, R. \& Curry A., TQM - a holistic view. The TQM Magazine, 12(1), pp. 11-17, 2000. doi: http://dx.doi.org/10.1108/09544780010287159

[30] Saad, G.H. \& Siha, S., Managing quality: critical links and a contingency model. International Journal of Operations \& Production Management, 20(10), pp. 1146-1163, 2000. doi: http:// dx.doi.org/10.1108/01443570010343717

[31] Savolainen, T., Towards a new workplace culture: development strategies for employeremployee relations. Journal of Workplace Learning, 12(8), pp. 318-326, 2000. doi: http:// dx.doi.org/10.1108/13665620010355566

[32] Naor, M., Goldstein M.S., Linderman, W.K. \& Schroeder, G.R. The role of culture as driver of quality management and performance: infrastructure versus core quality practices. Decision Sciences, 39(4), pp. 671-702, 2008. doi: http://dx.doi.org/10.1111/j.1540-5915.2008.00208.x

[33] Sadia, R., A System Dynamics Approach Linking Employee Health, Quality Culture and Organizational Effectiveness, PhD Dissertation, Virginia Polytechnic Institute and State University, Virginia, 2006.

[34] Harvey, L. \& Stensaker, B., Quality culture: understanding, boundaries and linkages. European Journal of Education, 43(4), pp. 427-442, 2008. doi: http://dx.doi.org/10.1111/ j.1465-3435.2008.00367.x

[35] Dellana, A.S. \& Hauser, D.R., Towards defining the quality culture. Engineering Management Journal, 11(2), pp. 11-15, 1999. doi: http://dx.doi.org/10.1080/10429247.1999.11415022

[36] Detert, R.J., Schroeder, G.R. \& Mauriel, J.J., A framework for linking culture and improvement initiatives in organizations. Academy of Management Review, 25(4), pp. 850-853, 2000. doi: http://dx.doi.org/10.2307/259210

[37] Goetzel, Z.R., The financial impact of health promotion and disease prevention programs why is it so hard to prove value? American Journal of Health Promotion, 15(5), pp. 277-280, 2001. doi: http://dx.doi.org/10.4278/0890-1171-15.5.277

[38] Aldana, G.S., Financial impact of health promotion programs: A comprehensive review of the literature. American Journal of Health Promotion, 15(5) pp. 296-320, 2001. doi: http://dx.doi. org/10.4278/0890-1171-15.5.296

[39] Abdullah, D.N.M.A. \& Lee, O., Effects of wellness programs on job satisfaction, stress and absenteeism between two groups of employees (attended and not attended). Social and Behavioral Sciences, 65, pp. 479-484, 2012. doi: http://dx.doi.org/10.1016/j.sbspro.2012.11.152

[40] Anderzen, I. \& Arnetz, B.B., The impact of a prospective survey-based workplace intervention program on employee health, biologic stress markers, and organizational productivity. Journal of Occupational Environmental Medicine, 47(7), pp. 671-682, 2005. doi: http://dx.doi. org/10.1097/01.jom.0000167259.03247.1e

[41] Grawitch, M.J., Gottschalk, M. \& Munz, D.C., The path to a healthy workplace: a critical review linking healthy workplace practices, employee well-being, and organizational improvements. Consulting Psychology Journal: Practice and Research, 58(3), pp. 129-147, 2006. doi: http://dx.doi.org/10.1037/1065-9293.58.3.129

[42] Rosen, H.R., The Healthy Company, Jeremy P. Tarcher/Perigee: New York, NY, 1992.

[43] Senge, M.P., The Fifth Discipline, Currency Doubleday: New York, NY, 1990.

[44] Oliva, R., Empirical validation of a dynamic hypothesis. Proc. of the Int. Conf. of System Dynamics, eds. G.P. Richardson \& Sterman, J. D, System Dynamics Society: Cambridge, MA, pp. 405-408, 1996.

[45] Forrester, W.J., System dynamics and the lessons of 35 years. In A Systems-Based approach to policy making, ed. K.B. De Greens, Kluwer Academic Publishers: Cambridge, MA, 1993. 